finance teams, staff costs include the full cost to the organisation including superannuation (13\%) and national insurance contributions.

Results $8(33.3 \%)$ of 24 SP were discharged from ED. 16(PSP : SPS $=7: 9)$ were admitted; 10 (62.5\%) accepted to have DC. Please see the results tabulated.

Conclusions Carefully organised DC for SP is safe, cost effective and meets with high patient approval and satisfaction.

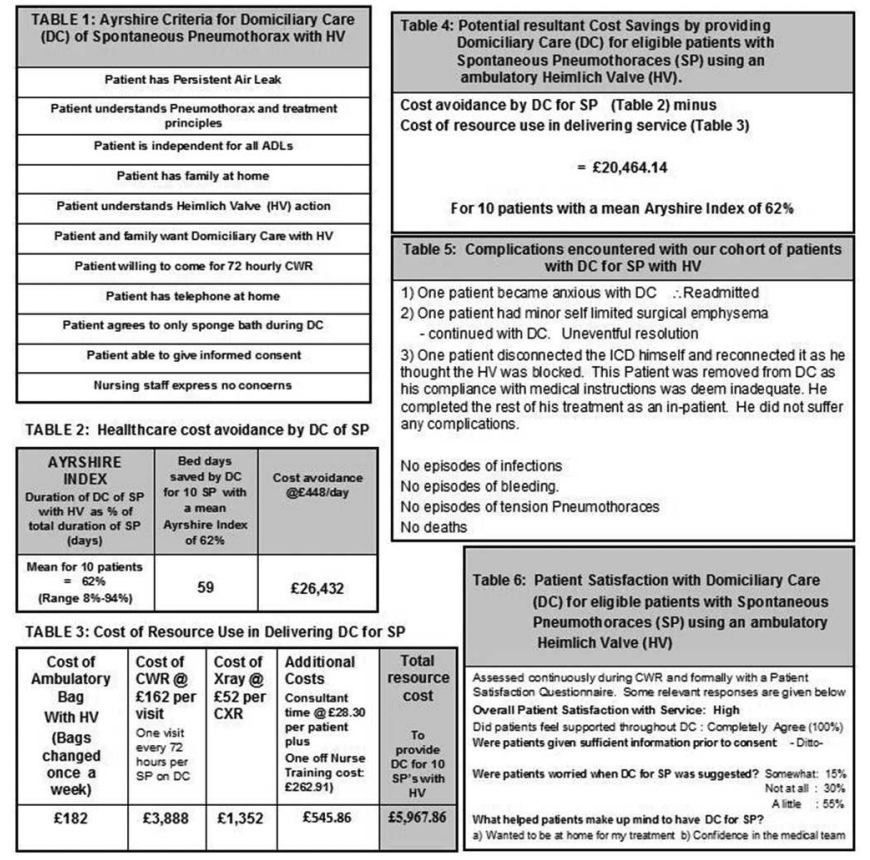

Abstract 211 Figure 1

\section{P212 SHOULD INTERCOSTAL TUBE DRAINAGE BE THE FIRST INTERVENTION IN THE MANAGEMENT OF PRIMARY SPONTANEOUS PNEUMOTHORAX WITH COMPLETE LUNG COLLAPSE?}

MB Ganaie, S Bikmalla, MA Khalil, MA Afridi, M Haris, IR Hussain; University Hospitals of North Staffordshire, Stoke-on-Trent, United Kingdom

\subsection{6/thoraxjnl-2013-204457.364}

Introduction and Objectives Primary Spontaneous Pneumothorax (PSP) is a common presentation with significant variation in severity and treatment strategies globally. There is no differentiation between 'large' PSP with complete lung collapse and 'large pneumothorax' in the current treatment algorithms. Previous studies comparing needle aspiration (NA) and intercostal tube (ICT) drainage for all PSP requiring intervention have shown no significant difference in immediate success rate, early failure rate and length of stay. We aimed to compare NA with ICT as the first intervention in those with complete lung collapse.

Methods Retrospective, observational study of 212 consecutive pneumothorax episodes between January 2012 and December 2012. Those with secondary spontaneous pneumothorax (SSP), history of trauma and iatrogenic pneumothorax were excluded. Pneumothorax with no visible aerated ipsilateral lung on plain chest radiograph was defined as 'complete lung collapse'. Patient records and plain chest radiographs on PACS were reviewed and data was analysed. Values of $\mathrm{p}<0.05$ were considered statistically significant.
Results Of the 212 episodes, 51 (33\%) were PSP. Median age was 29 years (IQR 22-38); male 33(75\%), female 18(25\%). 5 (1\%) were observed; $28(55 \%)$ had NA and $18(36 \%)$ had ICT as $1^{\text {st }}$ intervention. NA was successful in $13(46 \%)$ which is comparable to previous studies. $33(65 \%)$ required hospitalisation and median length of stay (LOS) for all PSP was 4 days. 18(35\%) required definitive surgical intervention.

Conclusion Our results show significantly better lung re-inflation rates with ICT as the first intervention in the management of PSP with complete lung collapse and there was no added benefit in performing NA. We propose a further sub-group of PSP with complete lung collapse in which NA should not be attempted, however well-designed prospective studies are required to validate this.

\begin{tabular}{|c|c|c|c|}
\hline & $\begin{array}{l}\text { Needle aspiration } \\
\text { as } 1^{\text {stintervention }} \\
(n=6)\end{array}$ & $\begin{array}{l}\text { ICT drainage as } \\
1^{\text {st }} \text { intervention } \\
(n=10)\end{array}$ & $P$ value \\
\hline Age, years, median(IQR) & $30(25-32)$ & $32.5(29-38)$ & $>0.99$ \\
\hline Smoking history & $1(17 \%)$ & $3(30 \%)$ & $>0.99$ \\
\hline Never smoked, $\mathrm{n}(\%)$ & $2(33 \%)$ & $1(10 \%)$ & 0.51 \\
\hline Ex-smokers, n(\%) & $3(50 \%)$ & $6(60 \%)$ & $>0.99$ \\
\hline \multicolumn{4}{|l|}{ Current smokers, $n(\%)$} \\
\hline Symptoms & $5(83 \%)$ & $8(80 \%)$ & $>0.99$ \\
\hline Chest pain, n (\%) & $4(67 \%)$ & $10(100 \%)$ & 0.125 \\
\hline \multicolumn{4}{|l|}{ Dyspnoea, n (\%) } \\
\hline Length of stay, days, median(IQR) & $5.5(4-10)$ & $9(4-13)$ & - \\
\hline Successful lung re-expansion, n(\%) & 0 & $6(60 \%)$ & 0.03 \\
\hline Requiring surgical intervention, $\mathrm{n}(\%)$ & $2(33 \%)$ & $4(40 \%)$ & $>0.99$ \\
\hline
\end{tabular}

\section{P213 NEVER EVENTS \& THE CHECKLIST MANIFESTO FOR INTERCOSTAL CHEST DRAINS}

B Khan; Darent Valley Hospital, Dartford, Kent, UK

10.1136/thoraxjnl-2013-204457.365

Background In the complex medical environment, clinicians commonly face varying challenges especially when undertaking invasive procedure with the risk of potential to harm patients. Checklists have a role in not only helping overcome human fallibility, but also ensuring that key steps are adhered to in order to ensure patient safety.

Intercostal chest drains are amongst the most invasive procedure undertaken in Internal Medicine, often out of hours and in emergent clinical situations, and possibly in less than ideal environments and with limited or no supervision. All of these factors have been highlighted in the 2008 UK National Patient Safety Agency (NPSA) report highlighting 780 events of harm including 12 deaths from intercostal chest drain insertions1. The NPSA Never Events2 list includes wrong site surgery, and in the respiratory discipline this encompasses the inserting of a chest drain on the wrong side. Never Events are preventable because: there is guidance that explains what the care or treatment should be; there is guidance to explain how risks and harm can be prevented; and there has been adequate notice and support to put systems in place to prevent them from happening.

Methodology A systematic review of available literature around chest drain insertion, proformas and checklists was conducted. 